\title{
An emerging HIV risk environment: a preliminary epidemiological profile of an MSM POZ Party in New York City
}

\author{
M C Clatts, L A Goldsamt, H Yi
}

Sex Transm Infect 2005;81:373-376. doi: 10.1136/sti.2005.014894

See end of article for authors' affiliations

.....................

Correspondence to: Michael C Clatts, PhD, Institute for International Research on Youth at Risk, National Development and Research Institutes, Inc, 71 West 23rd Street, 4th Floor, New York, NY 10010,USA; clatts@ndri. org

Accepted for publication 7 February 2005

Objective: To develop a preliminary epidemiological description of a men who have sex with men (MSM) "POZ Party," an emerging sex environment for HIV+ MSM.

Methods: As part of a pilot study in New York City in 2003, data were collected using a brief, behavioural intercept survey at entry to POZ Party events. Domains include demographic characteristics, history of HIV infection, motivations for attending POZ parties, lifetime and recent exposure to drugs (including use during POZ Party events), and recent sexual practices (both within both POZ Party venues as well as in non-POZ Party venues).

Results: Predominantly white and over the age of 30 , subjects in the sample include a broad range of years living with HIV infection. Motivations for using a POZ Party venue for sexual partnering include relief from burdens for serostatus disclosure, an interest in not infecting others, and opportunities for unprotected sexual exchange. High rates of unprotected sex with multiple partners are prevalent in the venue. Although the sample evidences high rates of lifetime exposure to illicit drugs, relatively little drug use was reported in these sexual environments. These reports are consistent with evidence from direct observation at the venues themselves, in which no drug use was apparent.

Conclusion: Serosorting among HIV+ MSM may reduce new HIV infections, a stated interest of both POZ Party organisers and participants alike. However, high rates of unprotected anal intercourse within these venues signal continued risk for STIs. Additionally, unprotected sexual contact with HIV partners and status unknown partners outside POZ Party venues heightens concern for diffusion of HIV superinfection.

$\mathrm{H}$ IV/AIDS surveillance reports in the United States indicate that although the incidence of HIV infection has slowed, new infections among men who have sex with men (MSM) continued to increase by $11 \%$ from 2000 to 2003. ${ }^{1}$ In New York City, for example, $42 \%$ of the 2772 new HIV cases reported among men in 2003 were associated with MSM transmission risk, while for $38 \%$ of reported new cases the risk was unknown or under investigation. If the unknown cases are excluded, MSM HIV transmission accounted for $68 \%$ of new HIV infections among men in New York City in 2003. ${ }^{2}$ These data are consistent with the available behavioural data, which also signal the high rates of sexual risk among MSM, including HIV positive (HIV+) MSM. For example, a recent internet based survey of a national sample of MSM found that $63 \%$ of the HIV+ MSM reported unprotected anal sex in the past 6 months. ${ }^{3}$

Historically, bars, bathhouses, and public sex settings have been prominent sources of sexual partnering among MSM. However, new types of environments for selection of sexual partners are also emerging, including "circuit parties," internet "chat rooms," and "sex parties," affording increased selectivity in both types of sexual partners and forms of sexual interaction. Little is known about the sexual behaviours of HIV+ MSM, including how and where they recruit sexual partners, the types of sexual roles and practices in which they engage, or their decision making surrounding with HIV status disclosure. ${ }^{4}$

Of specific concern in this report is the emergence of an "MSM POZ Party," a sexual environment organised for the explicit purpose of facilitating sexual exchange among HIV+ MSM. Unlike other types of environments that MSM may use for sexual partnering, such as bars or bathhouses, POZ parties are organised as "mobile events." They are held in different locations, which are modified on a temporary basis to accommodate the objectives of the event, including both generalised social activity as well as various types of sexual exchange. These environments first emerged in the middle 1990s in New York City, initially as a somewhat informal gathering of a small group of HIV+ MSM, in which recruitment was largely through word of mouth exchanges among the sexual networks of this group. However, they have become substantially more elaborate in recent years and are now held several times a month, with additional events during holidays and special occasions such as "Gay Pride Day." Information about the events is now posted on a website and through periodic announcements sent to a listserv which contains over 5000 addresses. Moreover, participants in the New York City POZ Party described below also reported participating in similar types of HIV+ sex parties in other US cities-including Miami, Ft Lauderdale, Los Angeles, San Francisco, Chicago, Denver, Palm Springs, Seattle, Boston, and Washington DC, as well as in Canada, Australia, and Western Europe, suggesting that the emergence of these sex environments is not limited to New York City.

There is limited public health research on MSM sex parties, and to our knowledge there are no published reports on sex environments that are exclusive to HIV+ MSM. In an effort to extend the information available about the emergence of these environments, we describe findings from a pilot epidemiological study conducted in a New York City based MSM POZ Party. We describe characteristics of men who participate in the venue, their goals and motivations for

Abbreviations: Al, anal intercourse; MSM, men who have sex with men; STI, sexually transmitted infections 
attending, and the types of drug and sexual interactions that are prevalent in a POZ Party venue. Additionally, we also briefly describe data on subjects' sexual practices outside POZ Party environments since they have relevance to our understanding of the epidemiological significance of the emergence of these environments, including spread of STIs and HIV superinfection.

\section{METHODS}

While some generalised social activity occurs, POZ parties are principally organised for the purposes of facilitating sexual exchange. Men come to the event with the expectation of relative anonymity. Consequently, using a POZ Party as a venue for research required some methodological adaptation. Two considerations were key in introducing research into the venue: brevity and privacy. Initially, methods of ethnographic observation and informal conversational interviews were used to establish a research presence in the venue, to foster rapport and trust between participants and the research team, and to substantively inform development of a behavioural survey. Subsequently, a brief intercept survey was introduced in the venue. Upon entry to the venue, the organiser of the event alerted participants to the presence of the research team and the general nature of the study. Subjects who indicated interest were then introduced to a member of the research team present in the venue. Research staff discussed the objectives and procedures of the study with each individual, including the areas of inquiry included in the survey, procedures for the protection of confidentiality, and an explicit acknowledgement of the right to decline participation. Verbal consent was obtained from all survey participants. These procedures, including recruitment and consent procedures, and the survey instrument itself, were approved by National Development and Research Institute's institutional review board before initiation of the survey data collection.

As noted above, the fact that the venue is organised primarily for the purposes of facilitating sexual interaction, rather than as a venue for research, placed some limits on the length of the intercept survey instrument that could be employed within the venue itself, thereby constraining both the range of topics included as well as level of detail that could be achieved. ${ }^{5}$

In general, the self administered survey required approximately 15-20 minutes to complete. Survey domains included demographic characteristics, history of HIV infection, current HIV treatment profile, year of first participation in POZ Party environments, motivations for participating in $\mathrm{POZ}$ parties, recent history of STIs, and current engagement in HIV treatment.

We used an occupational hazards model to assess discrete drug and sexual practices associated with participation in POZ Party environments, and focused our assessments on the last POZ Party the subject attended because the assessment tool was completed upon entry to the venue, and hence could not reliably capture what might occur in the current event from which the subject was being sampled. Based on our initial ethnographic observations that condoms were almost never used in the venue, and that therefore assessing their use would yield little analytic variability, questions on sexual practices focused on discrete sexual roles and sexual practices related to the exchange of semen (that is, insertive and receptive roles in oral and anal intercourse, whether the subject gave or received ejaculate).

In addition to roles and practices at the last POZ Party they attended, subjects were also asked to describe their last sexual encounter outside a POZ Party environment, including sexual exchanges organised through internet chat rooms, social venues, and a wide range of public and semi-public sex
Table 1 Characteristics of POZ Party attendees

\begin{tabular}{|c|c|}
\hline & $\%(\mathbf{n})$ \\
\hline Age (years) & $42.4(7.7 ; 20-61)^{\star}$ \\
\hline \multicolumn{2}{|l|}{ Ethnicity } \\
\hline White & $70.4 \%(81 / 115)$ \\
\hline Black & $6.1 \%(7 / 115)$ \\
\hline Hispanic & $14.8 \%(17 / 115)$ \\
\hline Other & $8.7 \%(10 / 115)$ \\
\hline Sex only with men & $\begin{array}{l}96.5 \%(111 / 115) \\
9.9(5.6: 2 \text { months to }\end{array}$ \\
\hline Years of seropositivity & $\begin{array}{l}4.9(0.0 ; 2 \text { monins to } \\
20 \text { years)* }\end{array}$ \\
\hline Current on HAART & $68.8 \%(75 / 109)$ \\
\hline STI $<1$ year & $33.6 \%(37 / 110)$ \\
\hline Ever attended POZ Party & $76.5 \%(88 / 115)$ \\
\hline First attended before 2000 & $35.3 \%(30 / 85)$ \\
\hline First attended in $2000-3$ & $64.7 \%(55 / 85)$ \\
\hline \multicolumn{2}{|l|}{$\begin{array}{l}\text { Primary (first) reasons for attending POZ } \\
\text { party† }\end{array}$} \\
\hline \multicolumn{2}{|l|}{ "Don't have to worry about disclosing my } \\
\hline $\begin{array}{l}\text { HIV status" } \\
\text { "Like having uninhibited or unrestricted }\end{array}$ & $34.6 \%(28 / 81)$ \\
\hline & $34.6 \%(28 / 81)$ \\
\hline $\begin{array}{l}\text { "Don't' have to worry about infecting } \\
\text { others" } \\
\text { "Like having sex with other HIV positive }\end{array}$ & $13.6 \%(11 / 81)$ \\
\hline men" "Like meeting other HIV positive men for & $8.6 \%(7 / 81)$ \\
\hline relationships" & $8.6 \%(7 / 81)$ \\
\hline \multicolumn{2}{|l|}{$\begin{array}{l}\text { Three reasons for attending POZ party } \\
\text { "Don't have to worry about disclosing HIV }\end{array}$} \\
\hline $\begin{array}{l}\text { status" } \\
\text { "Like having uninhibited or unrestricted }\end{array}$ & 140 \\
\hline $\begin{array}{l}\text { "Ilke having uninhibited or unrestricted } \\
\text { sex" }\end{array}$ & 115 \\
\hline $\begin{array}{l}\text { "Don't have to worry about infecting } \\
\text { others" }\end{array}$ & \\
\hline \multicolumn{2}{|c|}{$\begin{array}{l}{ }^{*} \text { Mean }(S D \text {; range) } \\
+ \text { Ranking score }=\text { first reason } \times 3+\text { second reason } \times 2+\text { third reason } \times\end{array}$} \\
\hline
\end{tabular}

environments. Details of sexual events external to a POZ Party included demographics of the partner, how the partner was recruited for sex, and the types of sexual roles and practices that occurred in the event. Both sex event assessments (that is, "last sex at POZ Party" and "last sex outside a POZ Party") included questions about alcohol and drug use, including independent measures of alcohol and drug use before, during, and after the event in which the sexual exchange occurred.

\section{RESULTS}

A total of 10 POZ Party events were sampled between July and December 2003, yielding 10-28 interviews per event (mean 17.6 subjects per event). The vast majority of subjects entering the venue (96\%) agreed to participate in the study, resulting in a total sample of 115 individual (non-duplicated) subjects whose serostatus was HIV positive.

Most were "white" (70\%), with modest representation among African-American (6\%), Latino (15\%), and other ethnic groups (9\%). Most (97\%) only have sex with men. Nearly all participants confirmed having HIV infection (95\%, 115/121). The sample evidences a broad time period in living

Table 2 Sexual practices at POZ Party

\begin{tabular}{ll}
\hline & $\%$ (n) \\
\hline Gave oral sex & $88.4(76 / 86)$ \\
Received oral sex & $93.0(80 / 86)$ \\
Receptive anal sex & $59.3(51 / 86)$ \\
Received ejaculate & $78.4(40 / 51)$ \\
Insertive anal sex & $72.1(62 / 86)$ \\
Gave ejaculate & $69.3(43 / 62)$ \\
\hline
\end{tabular}


with HIV, ranging from 2 months to 20 years since receiving their first HIV+ test (median $=10$, mean $=9.9, \mathrm{SD}=5.6$ ). Two thirds $(69 \%)$ are currently on HAART therapy. A third (33\%) reported having been treated for a STI within the past year.

Three quarters (75\%) reported having attended a POZ Party on at least one previous occasion, ranging from 1 month to 14 years since attending their first POZ Party. Based on a range of five possible options derived from initial ethnographic research in the POZ Party venue, subjects were asked to choose the three most important reasons that they attend POZ parties and to rank them in relative importance. "Not having to worry about HIV disclosure" was the most strongly endorsed reason (34\% ranked it first, 25\% second, and 18\% third). "Like having uninhibited or unrestricted sex" was the second most strongly endorsed reason (34\% ranked it first, $13 \%$ second, $11 \%$ third). "Don't have to worry about infecting others" was the third most strongly endorsed reason (13\% ranked it first, $23 \%$ second, $26 \%$ third).

Most (88\%) reported having performed oral sex on at least one person during the last POZ Party they attended and most (93\%) reported that someone performed oral sex on them during that same event. Nearly two thirds (59\%) reported receptive anal intercourse (AI) in the event and $78 \%$ of these received ejaculate; $72 \%$ engaged in insertive $\mathrm{AI}$ in event and $69 \%$ of these gave ejaculate. On average, subjects reported receiving ejaculate 1.6 times (median $=0, S D=2.9$, range: 0 12 ) and giving ejaculate 1.3 times (median $=0, \mathrm{SD}=2.9$, range: 0-20) (see table 2) As noted above, condoms are almost never used in the venue and differences between reports of having engaged in insertive or receptive AI versus giving or received ejaculate are accounted for by a practice in which the penetrating partner withdraws his penis before ejaculation.

With an interest in assessing the potential role of drug abuse in sexual decision making in these environments, subjects were asked about lifetime exposure to a wide range of substances, including marijuana, cocaine, crack, heroin, GHB, methamphetamine ("speed"), ketamine, MDMA ("ecstasy"), LSD, nitrite inhalants ("poppers"), PCP, Viagra, Xanax, and steroids. Questions included whether a subject has ever used a substance, the year when their first use of that substance occurred, whether they have ever injected any of these substances and the year they first injected them, and whether they have used any of these substances within the past 30 days. Additionally, we assessed whether they used any of these substances before, during, or immediately after the last POZ Party event in which they participated, the same event about which we obtained self reported information on sexual practices.
High rates of lifetime exposure to drugs were observed, particularly of so called "club drugs" such as cocaine $(63 \%)$, GHB (20\%), methamphetamine (47\%), and MDMA (51\%), as well as drugs that have been associated with sexual performance among MSM, including poppers (81\%) and Viagra $(30 \%)$. Reported use of these substances within the past 3 months was also high, though substantially less than the lifetime exposure levels.

However, relatively few subjects reported use of one or more of these substances in association with the participation in POZ parties, including before, during, or after the event. A minority reported use of one or more of these substances before the event, including GHB (1\%), speed (7\%), ketamine $(4 \%)$, and MDMA (2\%). Moreover, the limited drug use that was reported was confined to a small number of subjects (three men used speed alone, two used speed, MDMA, and ketamine, and one used speed, ketamine, MDMA, GHB, and Viagra). Similarly, relatively few reported use of one or more of these substances during the last POZ Party event they attended, including GHB $(2 \%)$, speed $(11 \%)$, and ketamine $(5 \%)$. Even fewer subjects $(6 \%, n=5)$ reported use of these substances after the last POZ Party they attended.

It is possible that subjects may have under-reported their use of drugs during the POZ Party. However, this seems unlikely. Following each event that was sampled, ethnographers prepared detailed ethnographic field notes regarding observations in the venue, with particular attention to drug use and drug paraphernalia. Assessment of field note data revealed scant mention of observed drug use other than "poppers." Moreover, no evidence of drug paraphernalia was documented.

\section{DISCUSSION}

While the inferences that can be drawn from this pilot study are limited, a number of items merit comment and consideration for further research: Firstly, participation in POZ parties may be one form of "serosorting. ${ }^{167}$ However, on the basis of these pilot data, it is unknown how prominent this single motivation is within the complex factors that may contribute to a decision to participate in a POZ Party. The fact that these venues are also relatively free of any expectation of condom use, and that they commonly feature opportunities for group sex, may also substantially contribute to participation. Additional research is needed to better understand the complex factors that may contribute to the sexual decision making of HIV+ MSM.

Secondly, while the study group as a whole evidenced high levels of lifetime exposure to a variety of illegal drugs, and more modest levels of current drug use, there is remarkably little drug use associated with participation in a POZ Party

Table 3 Drug use in lifetime, past 3 months, and before/during POZ Party

\begin{tabular}{lcccc}
\hline & Lifetime & Past 3 months & Before POZ Party & During POZ Party \\
\hline Marijuana & $82.0 \%(91 / 111)$ & $36.6 \%(41 / 112)$ & $4.7 \%(4 / 86)$ & $5.8 \%(5 / 86)$ \\
Cocaine & $63.1 \%(70 / 111)$ & $10.7 \%(12 / 112)$ & - & - \\
Crack & $15.7 \%(18 / 110)$ & $2.7 \%(3 / 112)$ & - & - \\
Heroin & $3.6 \%(4 / 110)$ & - & $1.2 \%(1 / 86)$ & - \\
GHB & $20.0 \%(22 / 110)$ & $11.6 \%(13 / 112)$ & $7.0 \%(6 / 86)$ & $2.3 \%(2 / 86)$ \\
Speed & $46.8 \%(52 / 111)$ & $17.9 \%(20 / 112)$ & $3.5 \%(3 / 86)$ & $4.5 \%(9 / 86)$ \\
Ketamine & $27.9 \%(31 / 111)$ & $8.9 \%(10 / 112)$ & $2.3 \%(2 / 86)$ & $3.5 \%(3 / 86)$ \\
MDMA & $51.4 \%(57 / 111)$ & $16.1 \%(18 / 112)$ & - & $7.0 \%(6 / 86)$ \\
LSD & $35.5 \%(39 / 110)$ & $0.9 \%(1 / 112)$ & - \\
Poppers & $81.1 \%(90 / 111)$ & $51.8 \%(58 / 112)$ & - & $1.2 \%(1 / 86)$ \\
PCP & $7.8 \%(8 / 110)$ & - & - \\
Viagra & $30.0 \%(33 / 110)$ & $14.3 \%(16 / 112)$ & $1.2 \%(1 / 86)$ & - \\
Xanax & $9.1 \%(10 / 110)$ & $3.6 \%(4 / 112)$ & - & - \\
Steroids & $3.6 \%(4 / 110)$ & $2.7 \%(3 / 112)$ & - & - \\
IDU & $8.9 \%(10 / 112)$ & $2.7 \%(3 / 112)$ & - & - \\
\end{tabular}

Before or during the last POZ party, 9 (10.5\%) men reported use of speed, ketamine, MDMA, GHB, or Viagra. 
itself, either before, during, or after the event. Given the prominent role attributed to drug use in high risk sexual practices of MSM, including associations between "club drug" use and recent increases in HIV and STIs, this suggests that a more complex understanding of the relation between drug and sexual risk is needed. ${ }^{8-10}$ At least in this group and within the specific sexual events sampled, high risk sexual practices were prevalent but were not associated with drug use.

Thirdly, the emergence of these types of sexual environments poses an opportunity for public health. It is not known how many of the participants in this venue have had previous involvement in behavioural research and hence how many might have been accessed in the types of recruitment venues employed in mainstream epidemiological research studies. Our overall impression is that very few of the participants in this study had any previous experience in behavioural research. However, the relatively high participation rates witnessed in this pilot suggests that research can be effectively implemented in POZ Party environments. POZ Party environments may represent potentially important resources of accessing sexually active HIV+ MSM and for acquiring a better understanding of their sexual decision making process.

\section{CONCLUSION}

POZ parties have the potential to contribute to reductions in the spread of HIV infection through self selection of HIV+ sexual partners. This goal was prominent in the organisers' stated rationale for developing POZ parties and also affirmed in subjects' motivations for participating in these environments. However, the potential public health benefits of the development of serosorting sexual environments among MSM, may be mitigated by the following considerations. Firstly, HIV+ MSM remain at risk for other STIs, notably a risk that may be heightened in an immunocompromised population. Secondly, subjects in this study also described the use of other types of environments for recruitment of sexual partners, including AI with HIV partners and status unknown partners. ${ }^{511}$ Thus, POZ parties are not the only source of sexual interaction among participants in these venues, and the high rates of unprotected sex observed within the venues and outside them suggests the potential for an epidemiological bridge between POZ Party and nonPOZ Party environments. Thirdly, and particularly in relation the previous consideration, the development of this bridge may facilitate diffusion of HIV superinfection, ${ }^{12}$ both among HIV+ men at POZ parties as well as their HIV negative sex partners in other venues.

Additional research is needed in order to elaborate our understanding of the nature of these emerging sexual environments and the role that they have in sexual partnering of HIV+ MSM. In particular, further research is needed about how HIV+MSM understand risk for STIs and HIV superinfection and also how they manage disclosure of serostatus in sexual encounters outside POZ Party environments.

\section{ACKNOWLEDGEMENTS}

Research described in this paper was supported by the National Institute on Drug Abuse (DA13558). We are also acknowledge the time and interest of the men who participated in the study. Finally, we are grateful for the support of Mr Robert Sandor who facilitated access to the venue and study population.

\section{Authors' affiliations}

M C Clatts, L A Goldsamt, H Yi, Institute for International Research on Youth at Risk, National Development and Research Institutes, Inc, 71

West 23rd Street, 4th Floor, New York, NY 10010, USA

\section{REFERENCES}

1 Center for Disease Control and Prevention. Diagnoses of HIV/AIDS - 32 States, 2000-2003. MMWR, 2004;53:1106-10.

2 New York City Department of Health and Mental Hygiene. HIV epidemiology program 4th quarter report, October, 2004.

3 Hirshfield S, Remien RH, Humberstone $M$, et al. Substance use and high-risk sex among men who have sex with men: a national online study in the USA. AIDS Care 2004;16:1036-47.

4 Gorbach P, Galea JT, Amani B, et al. Don't ask, don't tell: patterns of HIV disclosure among HIV positive men who have sex with men with recent STI practising high risk behaviour in Los Angeles and Seattle. Sex Transm Infect 2004:80:512-17.

5 Clatts MC, Goldsamt LA, Yi H. Drug and sexual risk in four men who have sex with men populations: evidence for a sustained HIV epidemic in New York City. J Urban Health 2005;82(1 Suppl 1):i9-17.

6 McConnell J, Grant R. Sorting out serosorting with sexual network methods. Boston, MA: Paper presented at, the 10th Conference Retrovirus and Opportunistic Infections, February, 2003.

7 Truong HM, McFarland W, Kellogg T, et al. Increases in "serosorting" may prevent further expansion of the HIV epidemic among MSM in San Francisco. San Francisco, CA: Paper presented at, the 11 th Conference Retrovirus and Opportunistic Infections, February, 2004.

8 Colfax G, Vittinghoff $E$, Husnik MJ, et al. Substance use and sexual risk: a participant- and episode-level analysis among a cohort of men who have sex with men. Am J Epidemiol 2004;159(10):1002-12.

9 Gillmore MR, Morrison DM, Leigh BC, et al. Does "high=high risk"? An event-based analysis of the relationship between substance use and unprotected anal sex among gay and bisexual men. AIDS Behav 2002;6:361-70.

10 Clatts MC, Welle DL, Goldsamt LA. Reconceptualizing the interaction of drug and sexual risk among MSM Speed users: notes toward an ethnoepidemiology. AIDS Behav 2001;5:115-30.

11 Clatts MC, Yi H, Goldsamt LA, et al. Sero-sorting and sexual practices among $\mathrm{HIV}+$ MSM in NYC: implications for epidemiology and prevention of HIV. Washington, DC: Oral presented at the 132nd Annual Meeting of American Public Health Association, November, 2004.

12 Blackard JT, Mayer KH. HIV superinfection in the era of increased sexual risktaking. Sex Transm Dis 2004;31:201-4. 